Научная статья

УДК 332.1

DOI 10.18101/2304-4446-2020-4-18-24

\title{
МЕТОДОЛОГИЯ ОЦЕНКИ ПОСЛЕДСТВИЙ ОГРАНИЧЕНИЙ ЖИЗНЕДЕЯТЕЛЬНОСТИ НАСЕЛЕНИЯ НА ТЕРРИТОРИИ НАЦИОНАЛЬНЫХ ПАРКОВ
}

\section{(C) Бардаханова Таисия Борисовна}

доктор экономических наук, ведущий научный сотрудник

tbard@binm.ru

\section{(C) Лубсанова Наталья Борисовна}

кандидат экономических наук, научный сотрудник

nlub@binm.ru

\section{() Максанова Людмила Бато-Жаргаловна}

доктор экономических наук, доцент, старший научный сотрудник

lmaksanova@yandex.ru

Байкальский институт природопользования СО РАН

Россия, 670047, г. Улан-Удэ, ул. Сахьяновой, 8

Благодарность: статья подготовлена в рамках выполнения государственного задания Байкальского института природопользования Сибирского отделения Российской академии наук (БИП СО РАН).

\begin{abstract}
Аннотация. Все регионы мира имеют сеть охраняемых территорий, что является одним из краеугольных камней в продвижении ценностей сохранения биоразнообразия, уникальных природных ресурсов и экосистемных услуг. Статья посвящена актуальным, но малоизученным методическим вопросам оценки социальных и экономических последствий правовых ограничений жизнедеятельности граждан и хозяйственной деятельности в границах охраняемых территорий. Методический подход, предлагаемый авторами, заключается в рассмотрении категории и стоимостной оценке убытков как совокупности реального ущерба и неполученных доходов, возникающих в результате ущемления (несоблюдения) прав граждан. Авторы разработали алгоритм оценки убытков, включающий три этапа. После систематизации правовых ограничений и их последствий для граждан на втором этапе формируется исходная база данных. На третьем этапе проводятся расчеты величин убытков населения, проживающего в границах национального парка, с использованием затратного, сравнительного и доходного методов. Количественная оценка убытков необходима для разработки механизмов интеграции охраняемых территорий в социально-экономическую жизнь проживающего в их границах населения.
\end{abstract}

Ключевые слова: ООПТ; национальные парки; правовые ограничения жизнедеятельности граждан; реальный ущерб; упущенные выгоды.

\section{Для цитирования}

Бардаханова Т. Б., Лубсанова Н. Б., Максанова Л. Б.-Ж. Методология оценки последствий ограничений жизнедеятельности населения на территории национальных пар- 
Т. Б. Бардаханова, Н. Б. Лубсанова, Л. Б.-Ж. Максанова. Методология оценки последствий ограничений жизнедеятельности населения на территории национальных парков

ков // Вестник Бурятского государственного университета. Экономика и менеджмент. 2020. № 4. C. 18-24.

\section{Введение}

В последние годы наблюдаются острейшие проблемы развития и функционирования населенных пунктов, расположенных в границах особо охраняемых природных территорий (ООПТ). Охраняемые территории занимают порядка $13 \%$ площади России, в границах федеральных ООПТ проживает около 2 млн человек ${ }^{1}$. Особую категорию среди ООПТ составляют национальные парки, совмещающие природоохранные и рекреационные функции. Национальные парки занимают промежуточное положение между охраняемыми территориями наиболее и наименее строгого режима охраны [1, с. 287]. Согласно российскому законодательству, нахождение населенных пунктов, на территории которых осуществляется повседневная жизнедеятельность граждан, допускается в границах национальных парков. В настоящее время на территории 27 национальных парков России расположено порядка 923 населенных пунктов, где проживает почти 371 тыс. человек ${ }^{2}$.

Российские охраняемые территории традиционно не рассматривались в контексте выполнения задач развития или повышения благосостояния местных жителей [2]. Поэтому запретительные меры по использованию лесных, растительных и животных ресурсов вынуждают местных жителей к браконьерству, а возникновение лесных пожаров воспринимается ими как возможность легального доступа к локальным рубкам [3, с. 11]. Многие исследователи отмечают, что правовые ограничения жизнедеятельности граждан и хозяйственной деятельности в границах охраняемых территорий неизбежно приводят к снижению привлекательности региона для проживания населения, а в итоге - к обезлюдиванию восточных территорий России $[4 ; 5]$.

В данной работе нами предпринята попытка разработать методические подходы к оценке социально-экономических последствий правовых ограничений жизнедеятельности населения в национальных парках. Общее понимание того, что население, проживающее на охраняемых территориях, ущемляется в правах собственности на земельные и имущественные активы, а также и на меры поддержки, может выражаться в конкретных количественных характеристиках, описывающих в наш прагматичный век стоимость «потерянного потенциала развития».

\section{Обзор литературы}

Обзор литературы показал, что вопросы оценки социальных и экономических последствий правовых ограничений жизнедеятельности граждан и хозяйственной деятельности в границах охраняемых территорий являются актуальными, но малоизученными. В значительной степени исследователи углублённо изучают

\footnotetext{
${ }^{1}$ Пояснительная записка к проекту федерального закона «О внесении изменений в Федеральный закон “Об особо охраняемых природных территориях" и отдельные законодательные акты Российской Федерации» [Электронный ресурc]. URL: http://sozd.duma.gov.ru/download/37D794C0-E1AC-4D21-B4E0-02D29178DD12 (дата обращения: 20.04.2020).

${ }^{2}$ Там же.
} 
вопросы стоимостной оценки всех видов биологических объектов и ресурсов, включая и особо охраняемые природные территории [6], оценки ценности и полезности использования и сохранения туристских ресурсов национальных парков на основе «контингент-метода» [7] или с использованием метода транспортных затрат [8], оценки экосистемных услуг [9; 10]. Существует обширная литература, посвященная методам экономической оценки ущерба от загрязнения окружающей среды [11], оценке прямых потерь продукции и упущенных выгод в результате экологических ограничений [12], разработке социально-экономических и компенсационных механизмов ${ }^{1}$ [13], оценке экономического ущерба региона от экологического фактора [14].

\section{Материалы и методы}

Под оценкой социальных и экономических последствий правовых ограничений жизнедеятельности населения авторы понимают стоимостное выражение убытков, возникающих в результате ущемления (несоблюдения) прав граждан, проживающих в населенных пунктах, расположенных в границах ООПТ.

Согласно пункту 2 статьи 15 Гражданского кодекса Российской Федерации, под убытками понимаются расходы, которые лицо, чье право нарушено, произвело или должно будет произвести для восстановления нарушенного права, утрата или повреждение его имущества (реальный ущерб), а также неполученные доходы, которые это лицо получило бы при обычных условиях гражданского оборота, если бы его право не было нарушено (упущенная выгода). Реальный ущерб, в свою очередь, подразделяется на уже понесенные или будущие расходы в связи с восстановлением нарушенного права и утрату или повреждение имущества. Что касается упущенной выгоды, поскольку она представляет собой неполученный доход, то есть предполагаемое пополнение имущественной сферы потерпевшего, которое произошло бы при нормальном развитии событий, если бы право не было нарушено, то следует принимать во внимание, что ее расчет, как правило, является приблизительным и носит вероятностный характер.

Определение количественного значения убытков населения, вызванных ущемлением (несоблюдением) прав граждан, проживающих в населенных пунктах, расположенных в границах национальных парков, заключается в стоимостной оценке изменений условий жизнедеятельности населения, которые происходят вследствие правовых препятствий для оформления земельных отношений. Определение реального ущерба в основном проводится методом прямого счета на основе затратного подхода. Необходимость уже понесенных и будущих расходов и их предполагаемый размер должны быть подтверждены обоснованным расчетом на основе калькуляции затрат и др. доказательств. При утрате имущества стоимость утраченного имущества определяется за вычетом износа, при повреждении - определяется сумма уценки или расходы на устранение повреждения.

В основе всех методов, созданных на сравнительном анализе, лежит сопоставление основных рыночных характеристик и параметров рынка, которые фактически имели место в период ограничения, с теми, которые имели место до

\footnotetext{
${ }^{1}$ Promoting Market-oriented Ecological Compensation Mechanisms: Payment for Ecosystem Services in China. Washington, DC: The World Bank, 2007.
} 
Т. Б. Бардаханова, Н. Б. Лубсанова, Л. Б.-Ж. Максанова. Методология оценки последствий ограничений жизнедеятельности населения на территории национальных парков

начала ограничения, а также на ином, но сопоставимом продуктовом/географическом рынке. Основное требование к выбранному эталону сравнения заключается в том, что он должен обоснованно отражать ситуацию, которая гипотетически могла бы иметь место на исследуемом рынке в отсутствие ограничения.

Размер неполученного дохода (упущенной выгоды) должен определяться с учетом разумных затрат, с учетом временного фактора. Во многих случаях необходимость оценивать убытки возникает через некоторое время после их причинения. Это означает, что пострадавший высчитывает размер убытка не только на момент его возникновения в прошлом, но и текущую стоимость убытка (то есть на момент осуществления оценки с учетом упущенных инвестиционных или коммерческих возможностей).

Для проведения анализа и расчета убытков могут быть использованы любые объективные источники информации:

- официальные статистические данные;

- сведения, полученные от налоговых и иных государственных органов;

- экспертные оценки и исследования;

- данные независимых информационных центров и средств массовой информации.

Результаты и обсуждение

Структура убытков, возникающих в результате ущемления (несоблюдения) прав граждан, проживающих в населенных пунктах в границах ООПТ, представлена на рис. 1.

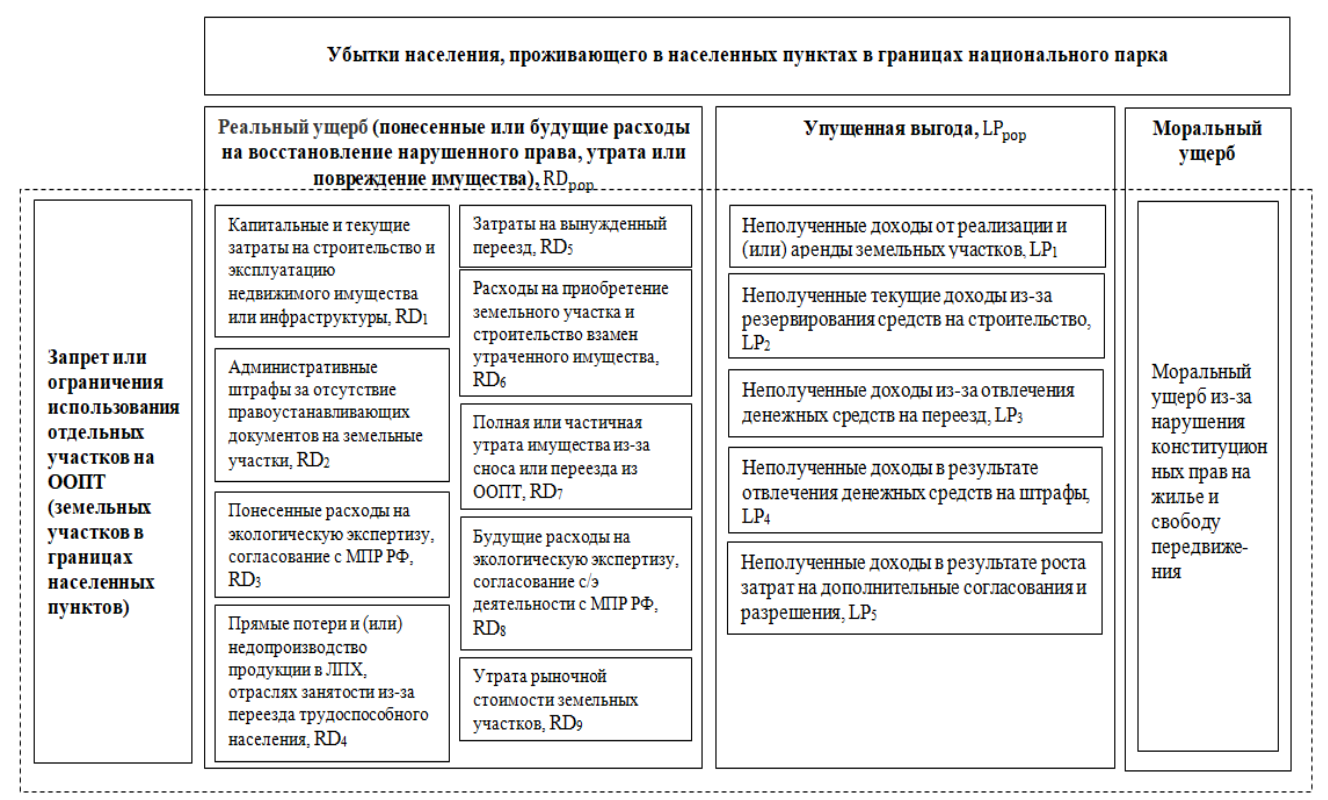

Рис. 1. Структура убытков, возникающих в результате ущемления (несоблюдения) прав граждан, проживающих в населенных пунктах в границах ООПТ Источник: авторская разработка 
Алгоритм стоимостной оценки убытков, возникающих в результате ущемления (несоблюдения) прав граждан, проживающих в населенных пунктах в границах ООПТ, включает три этапа (рис. 2).

На первом этапе проводится систематизация правовых ограничений жизнедеятельности населения и ведения хозяйственной деятельности в границах национальных парков, а также социальные и экономические последствия для граждан вследствие их действий. В качестве наиболее значимого ограничения выступают правовые препятствия оформления земельных отношений.

На втором этапе формируется исходная база данных: определяется набор показателей, который характеризует (описывает) воздействие вышеописанных ограничений на условия проживания, ведения хозяйственной деятельности и обеспечения социальных обязательств перед местным населением. При их отборе должны быть учтены принципы доступности информации, а также период с момента начала отказа в регистрации права собственности на землю.

\begin{tabular}{|ll|}
\hline \multicolumn{1}{|c|}{ Этап 1. Постановка задачи } \\
\hline 1.1. & Определение последствий правовых ограничений \\
\hline 1.2. & Определение географического ареала воздействия ограничений \\
\hline 1.3. & Определение временных границ действия ограничений \\
\hline
\end{tabular}

Этап 2. Формирование исходной базы данных

2.1. Определение категорий и оценка численности граждан, подвергающихся воздействию

2.2. Определение количественных показателей, характеризующих убытки населения

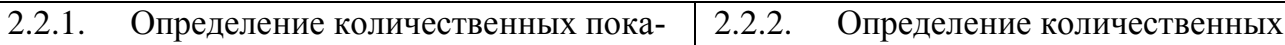
зателей, характеризующих реальный ущерб населению показателей, характеризующих упущенную выгоду

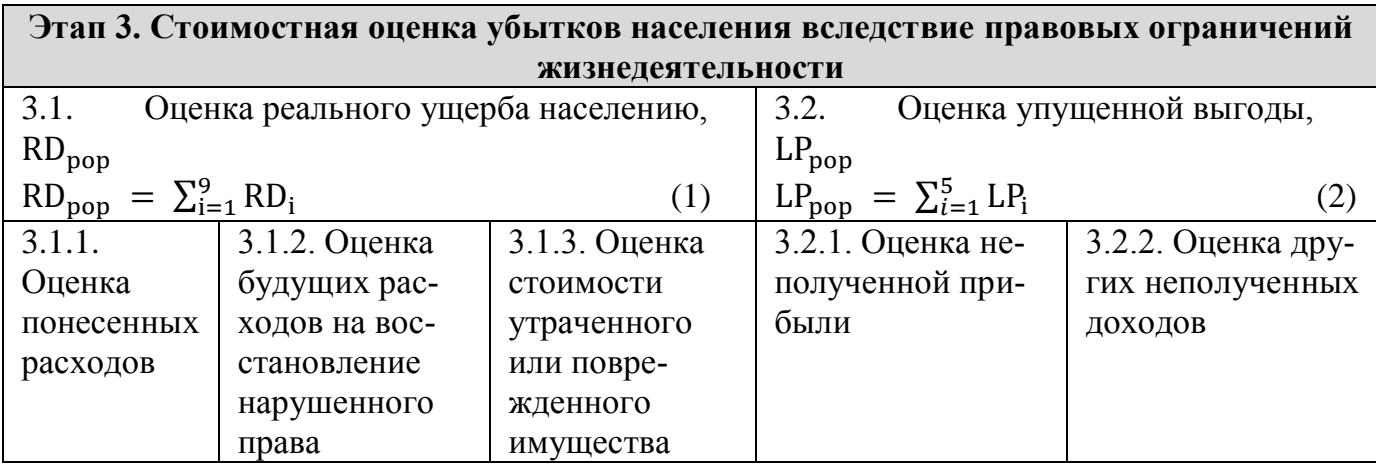

Рис. 2. Алгоритм стоимостной оценки убытков, возникающих в результате ущемления (несоблюдения) прав граждан, проживающих в населенных пунктах в границах ООПт Источник: авторская разработка 
Т. Б. Бардаханова, Н. Б. Лубсанова, Л. Б.-Ж. Максанова. Методология оценки последствий ограничений жизнедеятельности населения на территории национальных парков

На третьем этапе с использованием затратного, сравнительного и доходного методов проводятся расчеты величин убытков (реального ущерба и упущенных выгод) населения, проживающего в границах национального парка.

\section{Заключение}

Предлагаемая методика позволяет оценить социально-экономические последствия правовых ограничений жизнедеятельности населения в национальных парках, что может способствовать повышению заинтересованности лиц, принимающих решения, в выработке действенных мер по обеспечению баланса между сохранением уникальных природных ресурсов и созданием условий для проживания граждан и осуществления ими хозяйственной деятельности в границах охраняемых территорий.

\section{Литература}

1. Копылова С. Л. Национальные парки мира: региональные модели и тенденции развития // Теория и практика международного туризма: сб. ст. / под ред. А. Ю. Александровой. М.: КНОРУС, 2003. С. 298-317.

2. Данилина Н. Р. Российские заповедники в контексте мировой сети охраняемых природных территорий [Электронный ресурс]. URL: http://www.wildnet.ru/library/ view/?id=35 (дата обращения: 20.09.2020).

3. Тулохонов А. К., Гармаев Е. Ж. Байкальская проблема: история в документах (1960-2017). Улан-Удэ: Изд-во БНЦ СО РАН, 2017. 192 с.

4. Устинов А. Н., Чуксина В. В. Прибайкальский национальный парк: экопарадигма и права человека // Государственная власть и местное самоуправление. 2019. № 5. С. 3-9.

5. Сысоева Н. М. Проблемы собственности в развитии социального потенциала Забайкальского края // Ученые записки Забайкальского государственного гуманитарнопедагогического университета им. Н. Г. Чернышевского. 2013. № 1(48). С. 187-190.

6. Литвинова А. А., Игнатьева М. Н., Власова Л. В. Опыт экономической оценки особо охраняемых природных территорий // Вестник Уральского государственного горного университета. 2015. № 3(39). С. 57-62.

7. Choong-Ki Lee, Sang-Yoel. Han Estimating the use and preservation values of national parks' tourism resources using a contingent valuation method // Tourism Management. 2002. Vol. 23. P. 531-540.

8. Экономическая оценка туристско-рекреационных ресурсов Тункинского национального парка / Л. Б.-Ж. Максанова [и др.]; под ред. Л. Б.-Ж. Максановой. Улан-Удэ: Изд-во БНЦ СО РАН, 2002. 63 с.

9. Бобылев С. Н., Сидоренко В. Н., Лужецкая Н. В. Экономические основы сохранения водно-болотных угодий. M.: Wetlands International, 2001. 56 с.

10. Механизм сохранения биоразнообразия в деятельности ГПЗ «Костомушский» на основе оценки природных ресурсов и экосистемных услуг / под науч. ред. Г. А. Фоменко. Ярославль: Кадастр, 2006. 100 с.

11. Медведев П. В., Медведева О. Е., Тулупов А. С. Методика стоимостной оценки ущерба, причиняемого животному и растительному миру и среде обитания животных // Проблемы рыночной экономики. 2016. № 3. С. 4-13.

12. Бардаханова Т. Б., Алаева Т. Н., Федоров А. А. Экологические ограничения и экономические потери на особо охраняемых природных территориях (на примере национального парка «Тункинский») // Трансграничные аспекты использования природноресурсного потенциала реки Селенги в новой социально-экономической и геополитической ситуации: материалы междунар. науч. конф. Улан-Удэ, 2006. С. 39-44.

13. The regional peculiarities of the formation of ecology-oriented investment politics on the territories with ecological restrictions / S. Ayusheeva, A. Mikheeva, T. Bardakhanova, 
L. Maksanova, Z. Eremko // 18th International Multidisciplinary Scientific GeoConference SGEM 2018, Conference Proceedings. Vol. 18, Ecology, Economics, Education and Legislation. Issue: 5.3. Environmental Economics. P. 671-678.

14. Елгина Ю. М., Мекуш Г. Е. Оценка экономического ущерба региона от экологического фактора на примере Кемеровской области // Международный научноисследовательский журнал. 2014. № 2-2(21). С. 44-46.

\section{METHODOLOGY FOR ASSESSING THE CONSEQUENCES \\ OF RESTRICTIONS ON POPULATION ACTIVITY ON THE TERRITORY OF NATIONAL PARKS}

Taisiya B. Bardakhanova

Dr. Sci. (Econ.), Leading Researcher

tbard@binm.ru

Natalya B. Lubsanova

Cand. Sci. (Econ.), Researcher

nlub@binm.ru

Lyudmila B.-Zh. Maksanova

Dr. Sci. (Econ.), A/Prof., Senior Researcher

lmaksanova@yandex.ru

Baikal Institute of Nature Management SB RAS

8 Sakhyanovoy St., Ulan-Ude 670047, Russia

Abstract. All regions of the world have a network of protected areas, and they are the mainstay in promoting the values of biodiversity conservation, preservation of unique natural resources and ecosystem services. The article is devoted to the urgent, but little-studied methodological issues of assessing the social and economic consequences of legal restrictions on the life and economic activities of population within the boundaries of protected areas. In the framework of our methodological approach we considered the category and monetary estimate of losses as a combination of real damage and lost income arising from the impairment of the rights of citizens. We developed an algorithm for assessment of losses that includes three stages. After systematization of legal restrictions and their consequences for population, at the second stage we created the initial database. The third stage include the estimation of losses of the population living within the boundaries of national parks based on cost, comparative and profitable methods. A quantitative loss estimate is necessary to develop mechanisms for integrating protected areas into the socio-economic life of the population living within their boundaries.

Keywords: protected areas; national parks; legal restrictions on population activity; real damage; lost profits.

Статья поступила в редакцию 22.10.2020; одобрена после рецензирования 30.10.2020; принята к публикации 30.10.2020. 